\title{
MEDITATIVE TECHNIQUES IN PSYCHOTHERAPY
}

\author{
Wolfgang KRETSCHMER \\ Tübingen University
}

The psychotherapist who wants to employ techniques of meditation must first be able to meditate himself. The book by the German psychiatrist, J. H. Schultz, called "Autogenous Training" (auto: self; genous: originated) and sub-titled "Concentrated Self-Relaxation" (Das Autogene Training, 9th edition, Georg Thieme Verlag, Stuttgart, 1956 and Übungsheft für das Autogene Training, 8th edition, Thieme, Stuttgart, 1953), offers a step-by-step introduction to one technique of meditation. However, with meditation, as with psychotherapy, a study of the literature is seldom enough. A personal dedication is necessary. Without it, individual practice of meditation can be dangerous; especially the advanced stages of genuine meditation described by Schultz. In these advanced stages, after a general bodily relaxation has been achieved, symbolic fantasies are skillfully induced. Then colors and objects are visualized. One endeavors to experience a symbolic representation of ideas which are understood only abstractly, of one's feelings, of friends, and finally of higher moral questions, in a way which allows the psyche to make unconscious tendencies symbolically visible. Dreams are similar to meditation, except meditation gains the reaction of the unconscious by a systematic technique which is faster than depending on dreams.

But the Schultz technique only serves to raise, with a special emphasis, the question, "What is the goal of meditation?" Schultz sees this question clearly, but that this question is basically a religious one, or at least connected with religion, Schultz does not conclude. Therefore, he limits himself to the formulation of "basic existential values." This means the meditator is encouraged to strive toward a reasonable view of life orientated toward self-realization, psychic freedom and harmony, and a lively creativity. At best, one achieves a Nirvana-like phenomena of joy and release. Maybe Schultz conceals decisive experiences which go further; because of the basically unlimited possibilities of meditation, we can always await such an extension of his ideas.

The technique developed by Carl Happich, the former Darmstadt internist, is meditation of the most systematic kind, and also of the widest human scope. It begins with physiology and ends in religion. Happich developed it out of his literary and practical knowledge of Oriental techniques. He combined their wisdom with the experience of modern depth psychology. He set forth his fundamental principles in two small works entitled, "Symbolic Consciousness as the Starting Point of Psychic Treatment" (Das Bildbewusstsein als Ansatzstelle psychischer Behandlung, Zbl. f. Psychotherapie, Bd. 5, 1932) and "Symbolic Consciousness and the Creative Situation" (Bildbewusstsein und schöpferische Situation, Dtsch. med. Wschr., 1939, Nr. 2), and beyond these left only a small "Introduction to Meditation" (Anleitung zur Meditation, E. Rother, 3rd edition, Darmstadt, 1948), which is concerned with religious symbolism. Unfortunately, he did not live to set forth his life experiences in a grand scientific frame. His importance lies, above all, in the practical techniques which 
he began to spread among theologians when physicians demonstrated no interest in them.

Happich took the level of consciousness he called "symbolic consciousness," which seems to lie between consciousness and unconsciousness, as the point of departure for all creative production and, therefore, also for the healing process. On this level the "collective unconscious" can express itself through symbolism. It is in the activation of the possibilities of symbolic expression that Happich, as Schultz, sees the point of departure for meditation and its therapeutic possibilities.

How can we proceed practically? Assumed, as always, is the bodily solution which is attained systematically with the Schultz method or by more direct means. Happich placed great value in breathing as a graduated measure of the affective state which alters itself in the permissiveness of meditation. He encouraged, both before and during the therapeutic session, an increasing passivity of respiration. Most men can only achieve this through progressive breathing exercises.

After some experience with physiological reactions to breathing exercises has been gained, the first psychological exercise, the so-called "Meadow Meditation, can be attempted. The meditator must repeat to himself the words of his meditation-master and imagine that he (the meditator) leaves the room, goes through the city, over the fields, to a meadow covered with fresh grass and flowers and looks upon the meadow with pleasure. Then, he psychically returns the same way to the room, opens his eyes, and relates what he has experienced. When this exercise can be done freely (which usually requires a number of sittings) it is followed by the "Mountain Meditation."

The meditator, as in the first meditation, goes into the country and then slowly climbs a mountain. He passes through a forest, and finally reaches a peak from which he can view a wide expanse. In the third step, the "Chapel Meditation" is explored. In it, the meditator passes through a grove and reaches a chapel which he enters and where he remains for a long time. Lastly, Happich has the meditator imagine himself sitting on a bench by an old fountain listening to the murmur of the water.

What does all this mean? One who is familiar with dream symbolism knows immediately that the three central symbols (meadow, mountain, and chapel) to which the meditator is led have an "archetypal" significance even though, in everyday life, they are quite ordinary and in no way help to bring about an especially deep knowledge.

However, when a certain depth of meditation is attained, such symbols lose their ordinary meaning and their symbolical value is slowly revealed. As the meditator returns to the meadow, he does not experience things as he would in the ordinary world. Rather, the meadow provides a symbol of the hypnotic level of consciousness and stimulates the emotions on this level. The individual takes an ordinary situation as the means of experiencing the primordial content of the symbol of the meadow. The meadow presents youthful Mother Nature in her serene and beneficent aspect. In contrast, a forest is also inhabited by demons. The meadow represents the blossoming of life which the meditator seeks. It also represents the world of the child. When one meditates on the symbol of the meadow, he regresses to his psychic origin in childhood. Once there, he does not uncover sexual dreams of his childhood as might be expected. Nor does he find a "stump," which can also be a meaningful symbol. Rather, he returns to the positive, creative basis of his life. 
Every healthy man has in his psychic depths something corresponding to this meadow. He retains within him an active and creative "child." When a man is psychically sick, this "child" loses its positive and creative power. As the realm of this "child" is revealed through meditation on the symbol of the meadow, the meadow becomes a point of departure and crystallization for other symbols related to this psychic realm. These self-crystallized symbols are unmediated expressions of the individual's adaptation to the realm of the "child" within his psyche. A healthy man will have a satisfying experience of a meadow in the flush of Spring. He will populate the meadow with children or with the form of an agreeable woman. He will, perhaps, pick flowers and so on. In this way, the meditator discovers a symbolic representation of his psychic condition.

The psychically ill find it impossible to visualize a fresh meadow and during meditation cannot find one. Or the meadow may be seen as wilted or composed of a single stump. Or all sorts of disturbing, negative symbols may be scattered around. From such manifestations of illness, one gains a diagnosis which must then be translated into a therapy. Often, the meditation must be repeated many times until the crippling effects of the fundamental psychic problem are undone and the meditation can proceed normally. Analytic conversation with the psychotherapist normally aids the whole process.

In climbing the mountain, the meditator will generally symbolize some obstacle in his way so that he must prove himself. Climbing in this psychic sphere always implies "sublimation," in the Jungian rather than the Freudian use of the term. The words transformation, spiritualization, or humanization might convey the idea better than the word "sublimation." In any case, the climbing is a symbol of a movement during which man demonstrates his capacity to develop toward the goal of psychic freedom, the peak of human being. The passage through the forest on the way up the mountain gives the meditator the opportunity to reconcile himself with the dark, fearful side of nature.

With the symbol of the chapel, the meditator is led into the innermost rooms of his psyche where he faces the simple question of how he relates to the possiblilities of psychic transformation within man. When the meditator is able to comprehend the symbolic significance of the chapel, he can learn to use it to uncover and face in himself the central problems of human life. The chapel also provides a stage on which the resolution of these central human problems can be symbolically revealed. It is Happich's idea that the "religious function" is the most intimate and not an invisible factor in human life. Further, he believed that man, if he will be really healthy and psychically free, sometime and somehow must face these questions. One cannot avoid the fact that the special efficacy of Happich's therapy was the result of his religious attitude. He developed a Christian meditation.

That his system of meditation is based on sound psychological principles is confirmed by the work of the Jungian school. Dreams have been recorded where a mountain is seen in a landscape and on the mountain stands a church. Such symbolic pictures have been valued psychically as an indication of the end of the process of "Individuation," as a symbol of the attainment of "spirituality." But in meditation one does not wait until the needed symbols are produced spontaneously, as during dream analysis. Rather, the meditator is forced to occupy himself with certain symbols selected by the therapist until 
he has explored the fullness of their meaning.

Happich directed his meditators to a higher step which he called "Design (or Mandala, a Sanskrit word literally meaning circle, but more specifically an abstract design used especially in Tibetan Buddhism as a stimulus during meditation) Meditation." The design which is meditated upon is a kind of condensation, an abstraction of many symbols which are united into a generalized form. In the course of meditation on these designs, the meaning of the inherent symbolism can become obvious. With mandala meditation, the goal is not the production of extensive fantasy, but rather a lively meditation revolving around the central meaning of the design. Eventually, the meditator is directed to psychically identify himself with the symbol and to integrate the meaning of the symbol with his psychic life. Properly speaking, these designs are not used a technique of therapy, but rather in furthering the highest development of personality. An example of what can be experienced through meditation on a design can be read in the opening of Goethe's "Faust," where Faust beholds the design of the macrocosmos.

A still more abstract form of meditation is "Word Meditation," directed toward unfolding the central human importance of a word or a saying. Meditation on designs and words are of the greatest importance in furthering religious development.

Happich holds the healthy principle of the equality of rational and irrational activity during the course of meditation.

On the other hand, one should not meditate on symbols or designs which stimulate dangerous negative emotions, as for example, a snake or a scorpion. The subject of meditation should be purified through thousands of years' experience of the wisest men, and be of proven value as is the case with many Egyptian, Hindu, and German symbols and also the holy symbols of the Greek church. The first requirement of such symbols is the impression of their positive transforming power, which can be regulated by man's psyche.

R. Desoille, a Frenchman, described one of the newest and most original techniques in his book entitled, "The Waking Drean in Psychotherapy, an Essay on the Regulatory Function of the Collective Unconscious." (Le Rêve Eveillé en Psychotherapie, Presse Universitaire 1945, Paris. See also Psyche 1947, Number 2 and Psychoanalyse et Reve Eveille, 1950, Paris) His procedure is not meditation in the classical sense. The emphasis is shifted toward more conventional depth psychology. But it deserves discussion as a technique of actively relating to the unconscious.

Desoille treats his patients in a state of limited consciousness, in which he suggests that symbols be plastically visualized and actively experienced. He directs his patients to psychically wander wherever they choose, availing themselves of any means, a kind of wandering into which most patients soon fall. They experience, for example, the climbing of a mountain or a tower, ascent into the clouds, etc. Especially important is the climbing, for reasons already discussed. In this wandering, all possible hindrances are eliminated. As in dreams, various symbolic forms are manifested from the "Personal and Collective Unconscious" - in both auspicious and horrible aspects. Meeting "Archetypal" symbols is considered especially effective. The patient relates his psychic experiences as he has them, and the turning point of the method is the therapist's reaction to them. As he is informed in each moment of the psychological scene, the therapist suggests to the patient a symbolic means 
of changing his (the patient's) situation by climbing or descending. The therapist does not suggest the whole fantasy; rather, he gives only a direction and maintains control of the fantasy by offering helpful symbols which can serve as points of crystallization for the fantasy. The technique is a good one. In the climb, Desoille realizes and makes use of the human ability for creative sublimation. In the descent, the patient comes to know psychic productions from the sphere of man's instinctual nature. The patient is led to the psychological execution of what Goethe poetically described as the way "from heaven through the world to hell." In other words, he penetrates through the patient's whole psychic report and provides symbolic expressions of inherent libidinal tendencies which motivate men on various psychic levels. Decisive for Desoille is the experince of meeting the "Archetypes" which lead man to the absolutes of existence and the last decision, a decision of absolute and vast importance.

Desoille's valuation of the "Collective Unconscious" is more radical and consequential than Jung's, in that he (Desoille) holds that the meeting with the "Collective Unconscious" is a decisive and unavoidable presupposition of the therapeutic process.

Desoille holds that when the patient can relate himself to the "Archetypes of the Collective Unconscious," he can find in them the appropriate adjustment to the problems of life. The patient must learn to control the "Archetypes" within himself, to be free from them, and thereby lose his fear of them. He can then comprehend and resolve his personal conflicts within the larger context of man's inherent problems. Thus, the patient experiences his personal conflicts as having an impersonal and collective background. The motivational (libidinal) conflict is not resolved by being transferred upon the therapist, as in psychoanalysis; rather, the patient uncovers, in himself, the basic roots of the conflict. The goal of the technique is to direct the patient toward the fulfillment of his human potentialities through the creative development of man's basic biological impulses into a higher and harmonic order. With this idea, Desoille enters the realm of ethics and religion. Religious sensitivity is, for Desoille, the highest psychic state and the sourse of great activity.

Desoille's techniques require the therapist to possess a rare knowledge and understanding of symbolism and great psychological intuition in order to evaluate the waking dreams of his patients and to retain control of the process of psychological development which the waking dreams initiate.

The technique is, in a unique way, both diagnostic and therapeutic and the seemingly irrational procedure is worthy of note. Penetration of the psychic situation using reasonable conversation is given up. The therapeutic principle lies in the acceleration and furthering of effective development. It is a healing process which seeks the maximum transcendence of psychic limitations through symbolic ascensions and descensions. In this simple but most important principle, an earnest reminder can also be seen. Any therapist who would lead others to psychic heights and depths must, himself, be able to a attain these heights and depths of the psyche. Contemporary psychotherapists will have to begin by training themselves to ascend and descend through their own psyche and thereby experience the manifold components within man and the driving forces behind human life. Who will accept Desoille's hypothesis and begin to look up and climb?

Walter Frederking calls his psychotherapeutic technique "Deep Relaxation and Symbolism," which he sketched in "Psyche," 1948, Number 2. Frederking's technique is 
unsystematic, which implies nothing about its value.

Frederking also seeks freedom from dependence upon dreams by stimulating the unconscious to spontaneous productions of other kinds. To do this, he directs his patients in a progressive bodily relaxation during which they continue to describe their discoveries. One could also say he simply allows fantasy. The patient soon progresses from unclear visions to increasingly clearer productions of a kind of "symbolic strip thought." This symbolic thought, which has a significance similar to dream life, is allowed to flow by, scene by scene. The patient is both the playwright and the actors. He meets the contents of his "Personal Unconscious" and, to a degree, the "Collective Unconscious" and is able to relate their contents directly and dramatically to his psychic problems. One could also say that the patient is directed to enter "hell" to conquer the fiendish demons. This meeting with generally unrecognized aspects of himself brings about a spontaneous healing through various transforming symbols. Frederking holds that "in dreams and symbols man is led through every sphere of the psyche, during which the forms of psychic force are able to resolve themselves without the use of other means and deep-going transformations are effected."

Frederking also allows the therapy to be regulated by the autonomous healing force of the psyche. The technique is also irrational. Frederking knows, as all who work in these spheres know, that the therapist is in no way indifferent during the course of the therapy. It is true that he only occasionally injects himself to clarify and point out the course of the healing. But the therapist knows that the patient can only experience the most favorably significant symbols at his own opportunity. Although the therapist remains essentially passive and does not interfere, the patient is still in the therapist's psychic field and may receive direction or formulation of impulses.

Friedrich Mauz has described another technique in an article called "The Psychotic Man in Psychotherapy." (Archiv für Psychiatrie, 1948) This technique is not meditation in the strictest sense, but it is related to it in many ways. With psychotics, the previously described methods are very dangerous and, therefore, rejected. Accordingly, the Mauz method is a severely restricted form of meditation in which the unconscious is most carefully tackled and channelled into productive performance.

Mauz does not mention preference for any technical preparation. The technique develops directly out of conversation considering the role of conditioned reflexes occurring daily at the same time. This conversation is almost a monologue in which the therapist depicts the patient in plastic and sympathy-evoking representative pictures from childhood; the experience of a procession, Christmas celebration in the family, a children's song, etc. The depiction must have, for the patient, an appropriate and intuitive power as a "solvent picture." It should unlock and enliven the suppressed emotions of the psychotic so that later a real conversation can develop.

Mauz aims, as does meditation in other respects, at the emotional level of the patient. Basically, he also leads the patient to the Happich childhood meadow, the creative ground of the psyche. But rather than wait for the patient to produce, Mauz impregnates the meadow with symbols he knows will awaken positive feclings and meanings within the patient, such as the "security" of childhood with its guiltless pleasures. Through such feelings and symbols, the psychotic can again connect with the world around him. The creative power which 
flows from these feelings and symbols aids in closing the breach in the patient's personality.

It is noteworthy how Mauz describes important fundamental principles of meditation which he apparently discovered completely intuitively in genuine human behavior. The symbolic scene is the effector of the therapy, but only if it is experienced as real and actual; that is, as in meditation. "The picture must be personal and impersonal at the same time." It leads into the "sphere of impersonal knowledge and reality." "All that is loud, obtrusive, and harsh must be avoided." The decisive experiences of the past present themselves in the stillness. We must "identify ourselves with the psychotic opposites." "The therapist mixes himself into a common solution with the patient and allows his own comfort to wait." One could say that the therapist must meditate on the patient. He must allow himself to be caught by the patient as the patient is caught by formulations of their psychic power. This is the mystical unity between the therapist and the sick. One must "not only analyze the illness," but also "know the possible health." The therapist must have before him a conception of the completely harmonic man and seek where he can find it again to develop it.

What happens here is biologically and ethically one. "The emotion of security," says Mauz, "is both vegetative and psychic." With this idea Mauz grasps the whole anthropological aspect of therapy.

Decisive for Mauz before all else, is "the simple human relationship." It appears most significant to the writer that a professional scientist like Mauz comes through his experience with meditation with the conclusion that "humanness" is the highest principle of therapy, an idea which is still far from scientific medicine today.

Now to gather together the viewpoints which characterize and are combined in the various techiniques. All involve the active provocation of the unconscious, as the writer wishes to call it, in which the therapist chiefly has the function of a "birth helper." The patient is directed to place himself in relation to his unconscious, and thus make its creative possibilities available in the healing process. In contrast with the conscious, passive attitude employed in analytical methods of treatment, one takes an active, conscious, and oriented part in the healing process when using meditative techniques. Also in contrast with analytical methods, the meditative technique strives for a goal-directed, but individually adapted, formulation of man's nature in which a picture of the transformed man stands in the background. In this respect, Frederking is a relative exception. In contrast with the analyticalpsychological techniques, the basic exercises of meditation are not only applicable to healthy men, but are very useful.

There is a value in the analysis of abnormality. Emphasis on the analytical is usually emphasis on our psychic past. During meditation, there is more dependence on the tendency toward health in the psyche. The orientation is synthetic rather than analytic.

Meditation helps the patient to an expanded consciousness and impersonal experience and knowledge. Meditation has an advantage in that it allows the transition to religious problems to consummate itself in a completely natural way. The course of therapy is shorter with meditation because one is not dependent upon the mood of dreams and comes more quickly, both diagnostically and therapeutically, to the psychic conflict. Finally, with meditation, the patient does not ordinally transfer his problem onto the therapist and, therefore, the resolution of transference is usually unnecessary. 
Opposed to the great range and efficiency of meditation is only one severe limitation. Meditation is limited by the subjectivity of both the therapist and the patient. Not without purpose are all the described experiences ascribed to a creator which none of the important schools has equalled. Unfortunately, each successful therapist forms his own school. Desoille and Mauz certainly demonstrate most unusual intuitions and artistic ability. Not every patient is equally able to fruitfully experience the deeper levels of the psyche. Decisive is the problem of the psychic field of force described by Heyer, which is valid for all techniques which explore the deeper levels of the psyche. If the patient would resolve his intimate psychic problems, he must bring the symbols which expose them, either in dreams or in meditation, into higher levels of consciousness. Stimulation of the deeper levels of the unconscious is the art of psychotherapy, which really can be described only by the unscientific term "Exorcism." Exorcism is not only the result of a learnable technique, but is rather the result of the whole personal influence of the therapist on the patient. Therefore, with all these techniques, competent therapists are required. With one therapist, the patient may experience only the most banal contents of his unconscious; and with another, the patient may have a decisive experience of psychic depths. Thus, the psychotherapist must have a sense of vocation as well as a technique. A sense of vocation is the consequence of natural gifts and skill. Such skill is not learned as a craft nor as medical training, but rather through personal skill as it develops in the relationship between master and disciple. Great psychotherapy is unique and cannot be copied any more than a work of art. It is because the work of a master cannot be copied that one can learn from him.

Meditation has a good chance of eventually becoming one of the leading therapeutic techniques. All the newer systems with which the writer is familiar look for a development in this direction. But whether or not this development takes place depends completely on a deep-going reformulation of psychotherapeutic training and the practice of psychotherapy. It is of the greatest importance whether psychotherapy continues to be sought in the direction of meditation. We can only hope that psychotherapy will continue to develop into a genuine technique which can aid men in their goal of developing their highest psychic potentialities.

(Translated by William Swartley, Ph.D. from Zeitschrift für Psychotherapie und medizinische Psychologie. 1951, Vol.1, No.3) 